
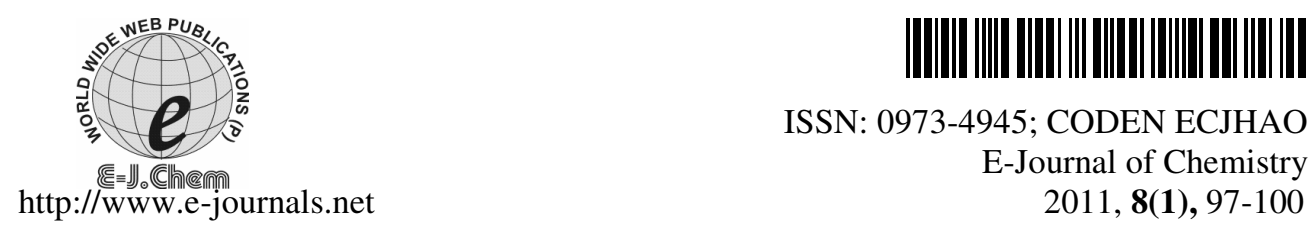

ISSN: 0973-4945; CODEN ECJHAO

E-Journal of Chemistry

2011, 8(1), 97-100

\title{
Synthesis of 3,7-Dinitro-1,3,5,7-tetraazabicyclo- $[3,3,1]$ nonane (DPT) Using Task-Specific Ionic Liquids as Recoverable Catalysts
}

\author{
L I U. XIAO-BING and L U. MING* \\ Chemical Engineering College \\ Nanjing University of Science and Technology \\ Nanjing 210094, P.R. China \\ lumingnj302@126.com
}

Reveived 3 May 2010; Accepted 18 July 2010

\begin{abstract}
A facile and efficient method for the synthesis of 3,7-dinitro-1,3,5,7tetraazabicyclo[3,3,1]nonane (DPT) has been developed starting from urea. In the procedure some task-specific ionic liquids was synthesized as a cheap and recyclable catalyst for the synthesis of DPT. The catalysts could be recovered and reused several times without noticeably decrease in the catalytic activity.
\end{abstract}

Keywords: 3,7-Dinitro-1,3,5,7-tetraazabicyclo[3,3,1]nonane (DPT), Ionic liquid, Catalyst, Nitration reaction.

\section{Introduction}

3,7-Dinitro-1,3,5,7-tetraazabicyclo[3,3,1]nonane (DPT) is a key precursor to octahydro1,3,5,7-tetranitro-1,3,5,7-tetrazocine (HMX) ${ }^{1,2}$, the most powerful explosive manufactured in bulk at present. Strecker et $a l^{3}{ }^{3}$ invented a process for producing DPT by utilizing nitrourea as starting material, but this approach involved long reaction times and unsatisfactory yield of DPT. Il'yasov et al. ${ }^{4}$ disclosed the application of $N, N$ '-dinitrourea (DNU) as intermediate for the synthesis of DPT, but no systematic synthetic studies were reported.

Recently, task-specific ionic liquids (TSILs) have emerged as a powerful alternative to conventional molecular organic solvents or catalysts due to their particular properties, such as undetectable vapour pressure, wide liquid range, as well as the ease of recovery and reuse ${ }^{5-8}$. The use of ionic liquids as reaction medium may offer a convenient solution to catalytic recycling problem. Some $\mathrm{SO}_{3} \mathrm{H}$-functional halogen-free acidic ionic liquids (Scheme 1) have been prepared and their catalytic activities have also been investigated $^{9-14}$. 
Herein we report an improved and facile preparation of DPT, starting from low cost urea. In the procedure urea was nitrified with $98 \%$ nitric acid and oleum $\left(20 \% \mathrm{SO}_{3}\right)$ as nitrating agent in the presence of task-specific ionic liquids (TSILs). DNU (1) was prepared in situ without isolation of the compound and the hydrolysis of DNU occurred in the presence of formaldehyde, since the subsequent neutralization with ammonia obtained DPT (2) (Scheme 2).<smiles>C[N+](C)(C)CCCS(=O)(=O)O</smiles>

[TMPSA][HSO $\left.{ }_{4}\right]$

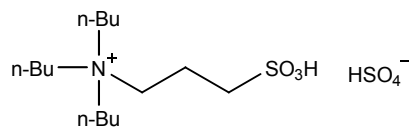

[TBPSA][HSO<smiles>CC[N+](CC)(CC)CCCS(=O)(=O)O[Na]</smiles>

[TEPSA][HSO $\left.{ }_{4}\right]$<smiles>C[N+](C)(C)CCCCS(=O)(=O)O</smiles>

[TMBSA][HSO<smiles>CC[N+](CC)(CC)CCCC[Sb]([O])(=O)O</smiles>

[TEBSA][HSO

\section{Scheme 1}

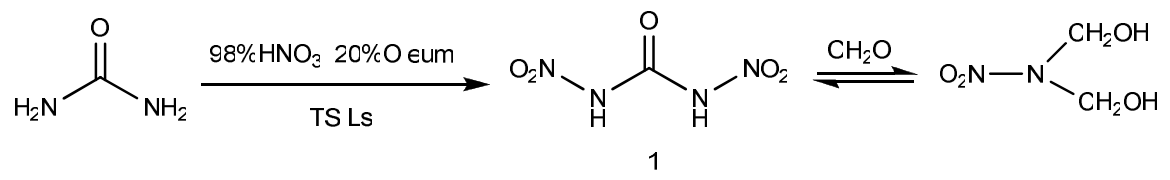<smiles>O=[N+]([O-])N1CN2CN(C1)CN([N+](=O)[O-])C2</smiles>

2

\section{Scheme 2}

\section{Experimental}

Melting points were determined on a Thomas Hoover capillary apparatus and were uncorrected. The IR spectra were recorded with a Bomem Michelson model 102 FTIR. ${ }^{1} \mathrm{H}$ NMR spectra were recorded on Bruker DRX (500 MHz) spectrometer. Elemental analyses were performed on a Yanagimoto MT3CHN recorder. Mass spectra were recorded on a VG ZAB-HS mass spectrometer using fast atom bombardment (FAB) ionization mode. All starting chemicals (AR grade) were purchased from commercial suppliers and used without further purification. The functionalized ionic liquids, [TMPSA] $\left[\mathrm{HSO}_{4}\right]$, [TEPSA] $\left[\mathrm{HSO}_{4}\right]$, [TBPSA][HSO4], [TMBSA][HSO $\left.{ }_{4}\right]$ and $[\mathrm{TEBSA}]\left[\mathrm{HSO}_{4}\right]$ were prepared by the procedures already reported in the literature ${ }^{13,14}$.

\section{Caution}

To handle these energetic materials, best safety practices (leather gloves, face shield) are strongly encouraged. 
Urea, $6 \mathrm{~g}(0.1 \mathrm{~mol})$, was added in portions to a mixture of $22.5 \mathrm{~g}$ of $98 \%$ nitric acid, $22.5 \mathrm{~g}$ of oleum $\left(20 \% \mathrm{SO}_{3}\right)$ and the appropriate ionic liquid at -5 to $0{ }^{\circ} \mathrm{C}$ under continuous stirring. After the addition the mixture was stirred for $1 \mathrm{~h}$ at 0 to $5^{\circ} \mathrm{C}$ and poured into $30 \mathrm{~g}$ of an ice-water mixture and $50 \mathrm{~mL}$ of a $37 \%$ formaldehyde solution was added at a temperature not exceeding $20^{\circ} \mathrm{C}$. The mixture was heated to $35{ }^{\circ} \mathrm{C}$, stirred for $30 \mathrm{~min}$, cooled and neutralized to $\mathrm{pH} 6$ with $25 \%$ aqueous ammonia at $20-25{ }^{\circ} \mathrm{C}$. It was then stirred for $45 \mathrm{~min}$ at $20{ }^{\circ} \mathrm{C}$ and the precipitate was filtered off, washed with water and dried at room temperature until constant weight. m.p. 209-210 ${ }^{\circ} \mathrm{C}$; published data: $205-206^{\circ} \mathrm{C}^{15}$. IR $\left(\mathrm{cm}^{-1}\right): 3032,2937\left(\mathrm{CH}_{2}\right) ; 1529,1288\left(\mathrm{NNO}_{2}\right) .{ }^{1} \mathrm{H}$ NMR (DMSO-d6): $\delta 5.49(\mathrm{~d}, 4 \mathrm{H}), 4.93(\mathrm{~d}, 4 \mathrm{H}), 4.11(\mathrm{~s}, 2 \mathrm{H})$. MS (FAB): $219\left([\mathrm{M}+1]^{+}\right)$. Anal. Calcd. for $\mathrm{C}_{5} \mathrm{H}_{10} \mathrm{~N}_{6} \mathrm{O}_{4}$ : C, 27.53; H, 4.62; N, 38.52; Found: C, 27.51; H, 4.59; N, $38.40 \%$.

\section{Results and Discussion}

In the initial experiments, we screened different functionalized ionic liquids for their ability to catalyze the reactions. The results are summarized in Table 1. All the five Brønsted acidic TSILs proved to be very active, leading to $69-75 \%$ yield of DPT in the presence of $10 \mathrm{mmol}$ TSILs (entries 2-6). In addition, ionic liquids containing the shorter length of alkyl chain are relatively cheaper. Hence, [TMPSA] $\left[\mathrm{HSO}_{4}\right]$ should be the best catalyst for this reaction among the five TSILs and the results of investigation of amount of [TMPSA] $\left[\mathrm{HSO}_{4}\right]$ are listed in Table 1 (entry 2, 7, 8). The results showed that $10 \mathrm{~mol} \%$ of [TMPSA] [HSO (based on urea) could most effectively catalyze the reaction and the higher amount of the catalyst did not improve the result to a greater extent.

Table 1. Synthesis of DPT catalyzed by different ${ }^{\mathrm{a}}$ TSILs

\begin{tabular}{ccc}
\hline Entry & TSILs, mmol & Yield, ${ }^{\mathrm{b}}$ \\
\hline 1 & None & 58 \\
2 & {$[\mathrm{TMPSA}]\left[\mathrm{HSO}_{4}\right](10)$} & 75 \\
3 & {$[\mathrm{TEPSA}]\left[\mathrm{HSO}_{4}\right](10)$} & 72 \\
4 & {$[\mathrm{TBPSA}]\left[\mathrm{HSO}_{4}\right](10)$} & 69 \\
5 & {$[\mathrm{TMBSA}]\left[\mathrm{HSO}_{4}\right](10)$} & 73 \\
6 & {$[\mathrm{TEBSA}]\left[\mathrm{HSO}_{4}\right](10)$} & 70 \\
7 & {$[\mathrm{TMPSA}]\left[\mathrm{HSO}_{4}\right](5)$} & 68 \\
8 & {$\left[\right.$ TMPSA] $\left[\mathrm{HSO}_{4}\right](20)$} & 74 \\
\hline
\end{tabular}

${ }^{a}$ Reaction conditions: urea $(100 \mathrm{mmol})$, nitric acid $(98 \%, 22.5 \mathrm{~g})$, oleum $\left(20 \% \mathrm{SO}_{3}, 22.5 \mathrm{~g}\right)$, formaldehyde (37\%, $50 \mathrm{~mL}),{ }^{b}$ Isolated yield

In the procedure of DPT synthesis, DNU was an important intermediate and urea was first nitrified to form nitrourea, then DNU. The nitric acid system can be thougt to be a molecular nitrating agent. The compound may be a nitronium ion carrier, which could not dissociate before reacting with nitrourea. There is an additonal consideration, based on the properties of the ionic liqud cations and anions. The TSILs used in this work have structures similar to those of tetrabutyl ammonium bromide (TBAB), so they could be used as phase tranfer catalysts ${ }^{16}$. It should facilitate the better solvatoin of a charged intermediate electrophilic species, $\mathrm{NO}_{2}{ }^{+}$-carrier, in the charged more highly polar TSILs. Furthermore, the presence of formaldehyde was requisite for the hydrolysis of DNU to form relatively stable $\mathrm{N}$-dimethylol nitramide and the TSILs could promote the reaction.

When optimizing the reaction condition, the recycling performance of [TMPSA] [ $\mathrm{HSO}_{4}$ ] was investigated. As shown in Figure 1, the catalyst could be reused at least five times without noticeable lowering of the catalytic activity. It was found that the methods to recover the [TMPSA] $\left[\mathrm{HSO}_{4}\right]$ were reduced pressure distillation and extraction with 
cyclohexane or ethers. For enviromental protecting and economic reasons and comparison with recycling of the traditional catalysts used in nitration, easy recycling performance is an atrractive property of the TSILs.

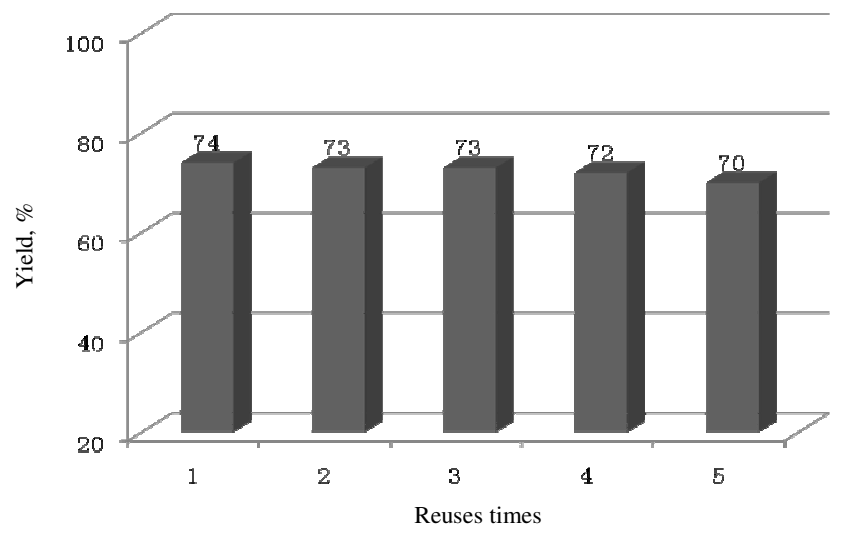

\section{Conclusion}

Figure 1. Reusability of [TMPSA] [ $\left.\mathrm{HSO}_{4}\right]$

In conclusion, a facile and efficient method for the synthesis of 3,7-dinitro-1,3,5,7tetraazabicyclo[3,3,1]nonane (DPT) has been developed catalyzed by task-specific ionic liquids (TSILs) in this paper. The catalysts can be reused without obvious loss of the catalytic activity. This approach could make a valuable contribution on the synthesis of DPT. Further investigations of nitration of DPT to obtain stable energetic materials are currently underway.

\section{References}

1. Radhakrishnan S, Talawar M B, Venugopalan S and Narasimhan V L, J Hazard Mater., 2008, 152(3), 1317-1324.

2. Radhakrisnan S, Sunil Kumar K, Soman T and Narasimhan V L, J Energ Mater., 2008, 26(2), 102-114.

3. Strecker R A and Randolph N J, US Pat., 1982, 4338442.

4. Il'yasov G S, ALobanova A A, Popov N I and Sataev R R, Russ J Org Chem., 2002, 38, 1739.

5. Welton T, Chem Rev., 1999, 99, 2071-2083.

6. Wasserscheid P andKeim W, Angew Chem Int Ed., 2000, 39, 3773.

7. Bates E D, Mayton R D, Ntai I and Davis J H, J Am Chem Soc., 2002, 124, 926-927.

8. Cole A C, Jensen J L, Ntai I, Tran K L T, .Weaver K J, Forbes D C and DavisJ H, $J$ Am Chem Soc., 2002, 124, 5962.

9. Fang D, Luo J, Zhou X and Liu Z, Catal Lett., 2007, 116, 76.

10. Fang D, Luo J, Zhou X, Ye Z and Liu Z, J Mol Catal A Chem., 2007, 274, 208.

11. Fang D, Liu Z and Zhou X, Chin Appl Chem., 2007, 24, 85.

12. Fang D, Luo J, Zhou X, Ye Z and Liu Z, Ind Eng Chem Res., 2006, 45, 7982.

13. Fang D, Gong K, Shi Q and Liu Z, Catal Commun., 2007, 8, 1463.

14. Fang D, Cheng J, Gong K, Shi Q and Liu Z, Catal Lett., 2008,121, 255.

15. Chute W J, Downing D C, Mckay A F, Myers G S and Wright G F, Can J Res B., 1949, 27, 218.

16. Jayachandran J P and.Wang M.L, Synth Commun., 2003, 33, 2463-2468. 


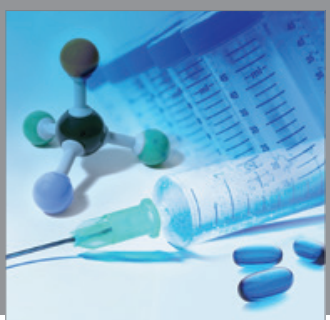

International Journal of

Medicinal Chemistry

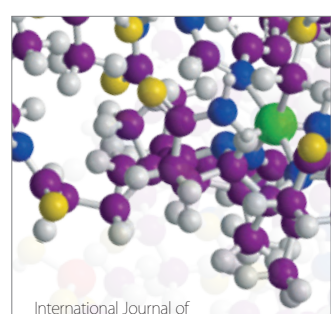

Carbohydrate Chemistry

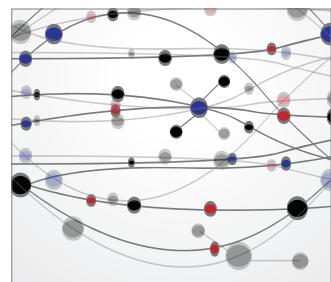

The Scientific World Journal
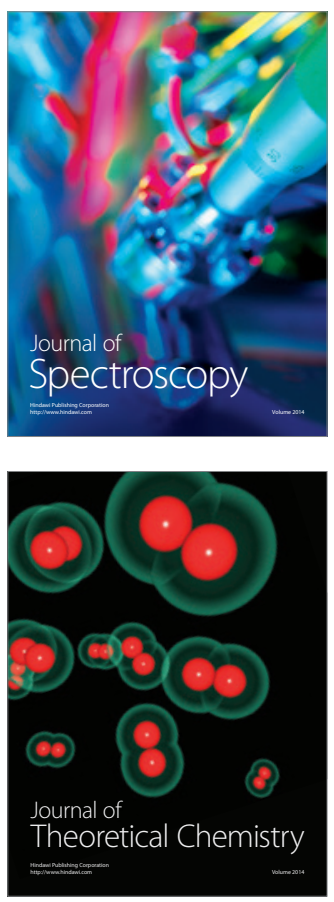
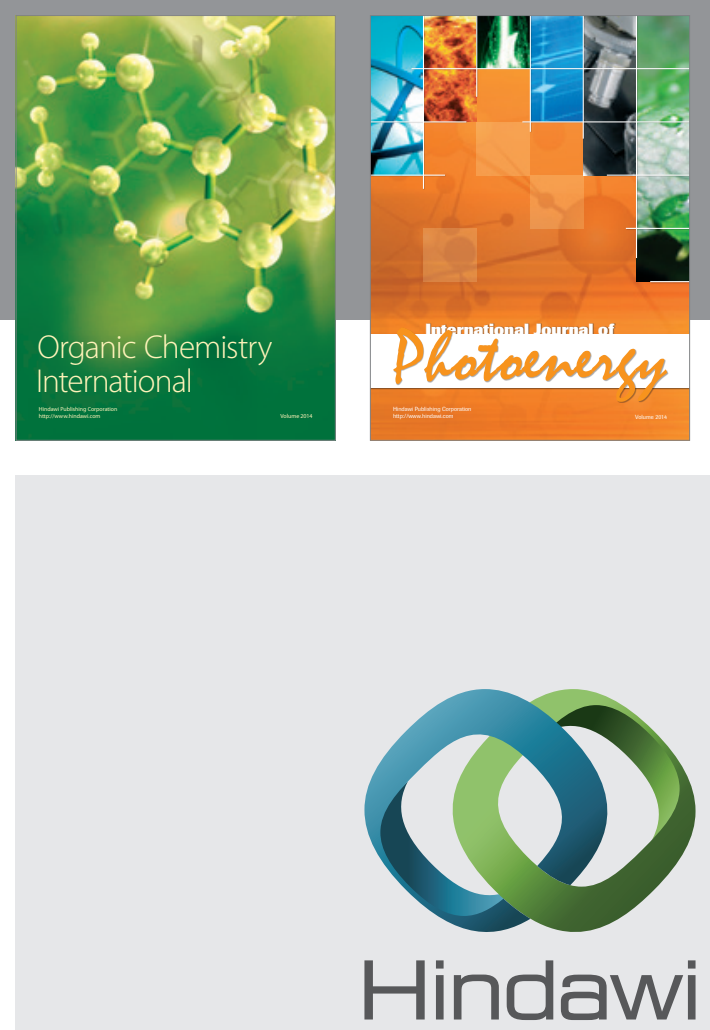

Submit your manuscripts at

http://www.hindawi.com
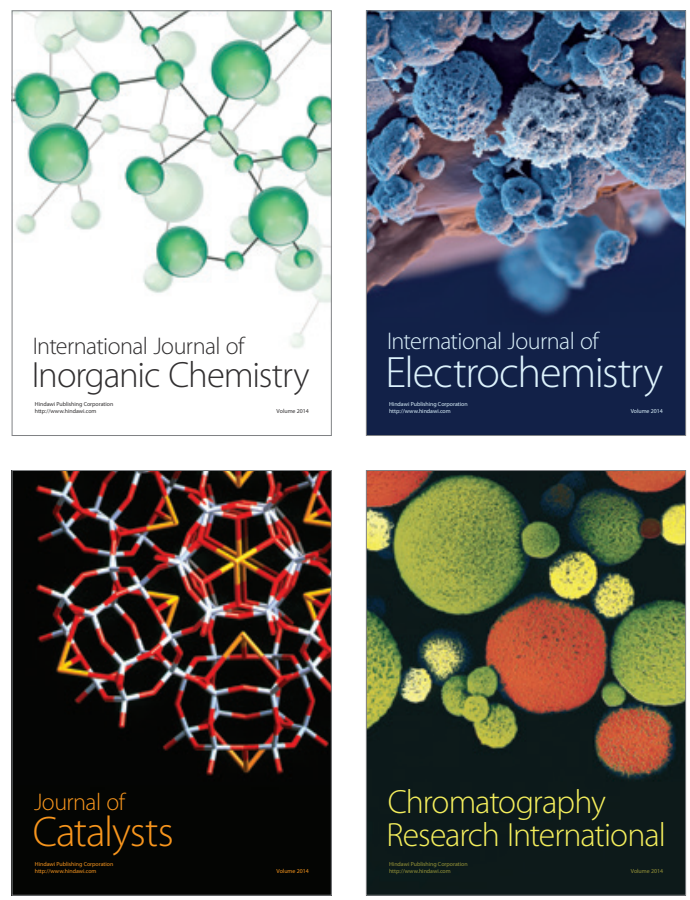
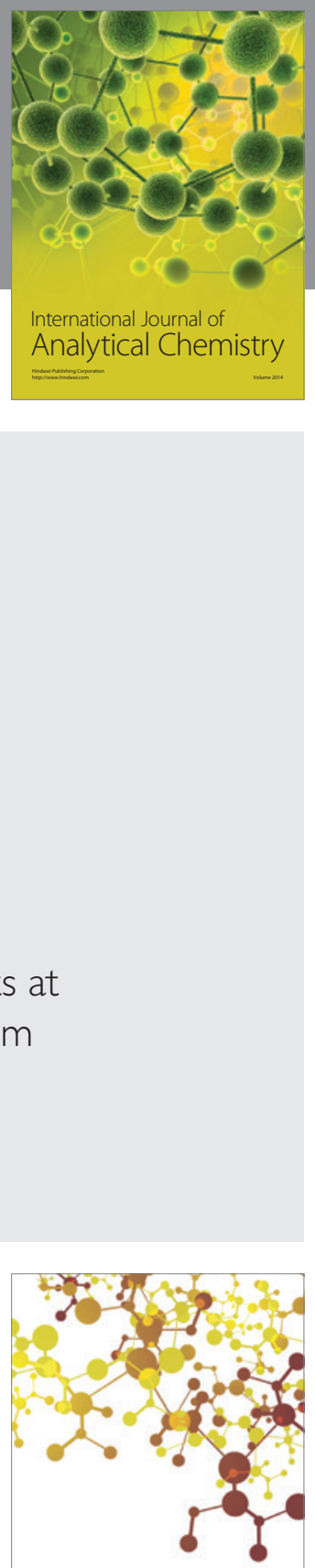

Journal of

Applied Chemistry
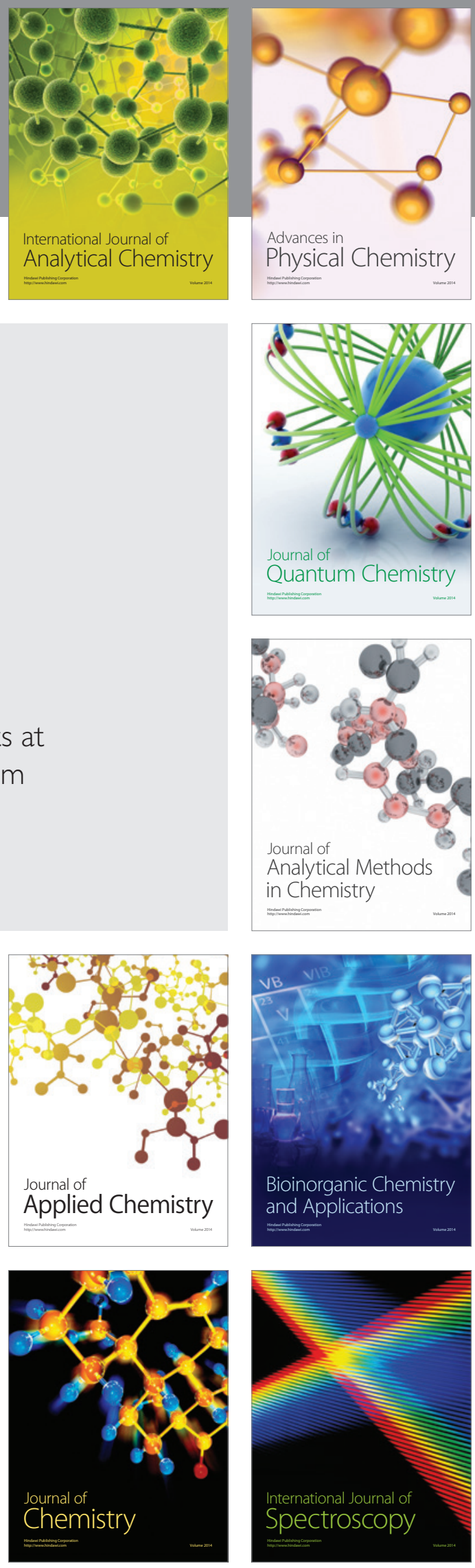